\title{
A degradation-based model for joint optimization of burn-in, quality inspection, and maintenance: a light display device application
}

Citation for published version (APA):

Feng, Q., Peng, H., \& Coit, D. W. (2010). A degradation-based model for joint optimization of burn-in, quality inspection, and maintenance: a light display device application. International Journal of Advanced Manufacturing Technology, 50(5), 801-808. https://doi.org/10.1007/s00170-010-2532-7

DOI:

$10.1007 / \mathrm{s} 00170-010-2532-7$

Document status and date:

Published: 01/01/2010

Document Version:

Publisher's PDF, also known as Version of Record (includes final page, issue and volume numbers)

Please check the document version of this publication:

- A submitted manuscript is the version of the article upon submission and before peer-review. There can be important differences between the submitted version and the official published version of record. People interested in the research are advised to contact the author for the final version of the publication, or visit the $\mathrm{DOI}$ to the publisher's website.

- The final author version and the galley proof are versions of the publication after peer review.

- The final published version features the final layout of the paper including the volume, issue and page numbers.

Link to publication

\footnotetext{
General rights

- You may freely distribute the URL identifying the publication in the public portal. follow below link for the End User Agreement:

www.tue.nl/taverne

Take down policy

If you believe that this document breaches copyright please contact us at:

openaccess@tue.nl

providing details and we will investigate your claim.
}

Copyright and moral rights for the publications made accessible in the public portal are retained by the authors and/or other copyright owners and it is a condition of accessing publications that users recognise and abide by the legal requirements associated with these rights.

- Users may download and print one copy of any publication from the public portal for the purpose of private study or research.

- You may not further distribute the material or use it for any profit-making activity or commercial gain

If the publication is distributed under the terms of Article 25fa of the Dutch Copyright Act, indicated by the "Taverne" license above, please 


\title{
A degradation-based model for joint optimization of burn-in, quality inspection, and maintenance: a light display device application
}

\author{
Qianmei Feng $\cdot$ Hao Peng $\cdot$ David W. Coit
}

Received: 6 March 2009 /Accepted: 11 January 2010 /Published online: 3 February 2010

(C) Springer-Verlag London Limited 2010

\begin{abstract}
This paper presents a degradation-based model to jointly determine the optimal burn-in, inspection, and maintenance decisions, based on degradation analysis and an integrated quality and reliability cost model. Degradation modeling plays an important role in reliability prediction and analysis for many highly reliable components and equipment, when the failures can rarely be observed. Unlike traditional applications, quality and reliability must be considered simultaneously for devices subject to degradation, because quality inspection decisions often impact anticipated reliability and failure-time distributions. This paper presents an integrated model to jointly optimize quality and reliability for devices subject to degradation, with a focus on burn-in, quality inspection, and maintenance policies. Based on the degradation modeling and analysis, the reliability function and the time-to-failure distribution are derived under the condition that the quality inspection is applied following the burn-in period. The optimal burn-in, quality inspection, and preventive maintenance policies are determined by minimizing the expected total cost per usage lifetime. The proposed model is illustrated using the application of light display devices, in which the degradation path follows a negative shifted lognormal distribution with a random failure threshold. A numerical example is provided to illustrate the application of our model to the light display devices.
\end{abstract}

Q. Feng $(\bowtie) \cdot$ H. Peng

Department of Industrial Engineering, University of Houston,

Houston, TX 77204, USA

e-mail: qmfeng@uh.edu

D. W. Coit

Department of Industrial and Systems Engineering,

Rutgers University,

Piscataway, NJ 08854, USA
Keywords Degradation modeling · Burn-in procedure . Quality inspection · Preventive maintenance · Negative shifted lognormal distribution $\cdot$ Light display devices

\section{Introduction}

Modern electronic, mechanical, and other engineering systems are becoming increasingly reliable with the advancement of manufacturing technologies. As a result, it often takes an unacceptably long time to obtain failure-time data, even under accelerated conditions, for the traditional failure data analysis, distribution fitting and reliability prediction. The design of highly reliable systems can benefit from a methodology for reliability analysis based on limited failure data, such as degradation-based analysis. Degradation modeling and analysis has attracted considerable attention from researchers in statistics and reliability since the early 1990s. It is a convenient and analytically sound method to estimate failure-time distributions and predict reliability, which has been successfully applied to many applications. Examples of degradation include the wear on rubbing surfaces of a microengine [1], the degrading light intensity of vacuum fluorescent displays (VFDs) [2], and the increasing crack size on microstructures [3].

Previous studies on degradation have been focused on developing degradation path models and estimating time-tofailure distributions, using experimental design to improve reliability, and exploring preventive maintenance policies for continuously monitored degrading systems. Lu and Meeker [3], and Meeker et al. [4] developed general statistical models to estimate the time-to-failure distribution from degradation measures. Singpurwalla [5] provided an overview of a class of stochastic failure models that can be used for systems affected by dynamic environments. Kharoufeh 
[6] derived the explicit probability distribution of the random failure time for single-unit systems that deteriorate continuously and additively due to the influence of a random environment modeled as a general, finite-state Markov process. Kharoufeh and Cox [7] presented a degradationbased procedure for the estimation of full and residual lifetime distributions for single-unit systems using real sensor data. $\mathrm{Lu}$ et al. [8] proposed a model with random regression coefficients and a standard-deviation function for analyzing linear degradation data. Bae and Kvam [2] introduced a loglinear degradation model with an unknown change point to characterize nonlinear degradation paths representing incomplete burn-in during the manufacturing process. Gebraeel et al. estimated residual life distributions based on sensory-updated data using a neural network approach $[9,10]$, a Bayesian approach [11], and for components with exponential degradation patterns [12]. Huang and Dietrich [13] utilized the natural ordering of performance degradation data to fit a truncated Weibull distribution to model reliability.

Unlike traditional applications where quality and reliability are often decoupled, they must be considered simultaneously for devices subject to degradation. Quality inspection decisions often impact anticipated reliability and failure-time distributions for devices that degrade over time. Therefore, for systems with degradation characteristics, manufacturing decisions should be determined by taking into account quality at the manufacturing phase and reliability during system operation simultaneously. This paper presents an integrated model to jointly optimize quality and reliability for devices subject to degradation. Specifically, we study the burn-in, quality inspection, and maintenance decisions that impact quality and reliability of devices.

Different burn-in, quality inspection, and preventive maintenance approaches have been studied separately. Preventive maintenance is often implemented to delay or avoid unexpected failures, which includes periodic maintenance and predictive (condition-based) maintenance. Grall et al. [14] developed a maintenance cost model for determining the optimal inspection schedule and replacement threshold for a single-unit degrading system. To reduce the uncertainty in cost estimates, Liao et al. [15] proposed a condition-based maintenance model for a continuous degradation process by taking into account imperfect maintenance and a short-run availability constraint. $\mathrm{Lu}$ et al. [16] presented a preventive condition-based maintenance approach based on monitoring, modeling and predicting system deterioration. Drapella and Kosznik [17] developed a model to determine equilibrium of burn-in and preventive replacement periods. Jiang and Jardine [18] examined the effectiveness of jointly applying burn-in and preventive replacement policy for situations where the failure time follows a mixture distribution.
However, there is no previous research for determining these quality policies to optimize quality and reliability simultaneously. This integrated strategy can reduce cost and increase customer satisfaction in the long run. We will develop a comprehensive analytical model to jointly determine these policies that is not currently available in the literature, and this complex general model can be adapted to different system designs. In this research, we illustrate our proposed model using the application of light display devices whose brightness degrades over time. Although degradation modeling of light display devices has been studied for burn-in process [2] and through experimental design for improving reliability [19], a comprehensive approach to jointly optimize quality and reliability is not available in the literature.

This paper is organized as follows. Section 2 describes the manufacturing and operation process of a typical light display device that involves burn-in procedure, quality inspection and maintenance. The integrated model for quality and reliability is developed in Section 3 based on the degradation modeling of luminosity. The impact of quality inspection on anticipated reliability and failure-time distributions is also explored in Section 3 before the integrated model is introduced. Section 4 presents the case study of a fluorescent lamp to illustrate the application of the proposed model. The paper is concluded in Section 5.

\section{Manufacturing and operation of light display devices}

For light display devices that are used under safety-critical environments, such as control panels in aircrafts and surgery lights in medical operations, the critical performance characteristic is the luminosity that is related to brightness. Failure of such devices has been traditionally defined in terms of the degradation in luminosity over time. For example, the industry standard definition for the lifetime of plasma display panels (PDP) and vacuum fluorescent displays (VFD) is the time at which their luminosity falls below $50 \%$ of its initial luminosity [2, 20]. Failure of fluorescent lamps (FL) is defined as the time when a lamp's luminosity falls below $60 \%$ of its luminosity [19].

During the manufacturing of light devices, chemical processes result in impurities in the phosphor contained in the tube, which degrade the light display quality [2]. To provide high-quality devices to customers, all the finished light devices must go through a burn-in procedure that is an essential step to remove harmful impurities remaining in light devices [2, 19]. The burn-in procedure is typically implemented after the manufacturing process where manufactured units are operated for a short period of time to remove weak or defective parts. Selection of the burn-in time is usually made based on cost, industry standards and 
time restrictions. An effective burn-in schedule should be determined that it is long enough to induce the defective units to fail, but not too long to impinge on the required lifetime of devices [21].

After the burn-in procedure, all devices are inspected to screen-out defective items whose output luminosity is lower than a certain level or a specification limit [19]. Automatic nondestructive testing systems can be implemented to provide $100 \%$ inspection [22]. A specification limit is usually determined by minimizing quality loss of the system at the initial state of devices [23-25]. However, this can be inefficient for the manufacturing of light devices without considering the degradation during field operation, as it may lead to unsatisfactory high maintenance costs during the device's life cycle due to early failures.

During field operation, the luminosity of light devices degrades leading to quality deterioration and reliability concerns. The cost of an impending failure sometimes makes it economical to replace an aged device with a new one, especially when the light device is used under safety-critical environments such as control panels in aircrafts and surgery lights in medical operations. An optimal preventive maintenance (PM) policy should be implemented to prevent failures due to the degradation in luminosity. For some applications, replacement can be done based on condition monitoring, but for many other applications, particularly those with large inventories of lights, age-dependent PM policies are implemented due to the inaccessibility of the components or impracticality of monitoring and tracking a large inventory. Under the age-dependent PM policy, a device is replaced at its age $\tau$ or failure, whichever occurs first, where $\tau$ is a fixed duration [26]. The replacement interval $\tau$ is an important decision variable to be optimized in order to achieve an acceptable reliability as well as minimize the total cost.

This paper aims to establish a mathematical model that can be used to determine optimal burn-in, quality inspection and preventive replacement policies simultaneously. The joint optimization model is necessary because the burnin time, inspection limit and replacement interval interact with each other, which impacts the degradation path over the device life cycle. By rewarding high system reliability and penalizing the quality loss due to variation, the proposed model can determine the optimal burn-in time, specification limits for inspection and an optimal replacement interval. Light display devices that degrade over time are used to illustrate the application and usefulness the proposed model.

\section{An integrated degradation-based model}

Consider a light display device (PDP, VFD, or FL) whose failure occurs when its luminosity falls below a certain percentage (e.g., 50\%, 60\%) of its initial luminosity. In degradation analysis, this type of failure has been referred to as "soft" failures, as opposed to "hard" failures when systems or components stop functioning abruptly. To simultaneously improve quality and reliability over the lifetime of light display devices, a systematic burn-in, inspection and preventive replacement procedure is depicted, as shown in Fig. 1 [21].

\subsection{Degradation modeling and analysis}

It is known that the luminosity for several types of VFDs, FLs, and PDPs decreases exponentially over the majority of the device life cycle, and the logarithm of the luminosity at time $t, X(t)$, can be expressed as [19]

$X(t)=\ln \Lambda(t)=\theta-\lambda t$

where $\Lambda(t)$ denotes the luminosity at time $t, \theta$ is the logtransformed initial luminosity, and $\lambda$ is the rate of degradation. This degradation path is appropriate after the burn-in procedure when the degradation is stable [2]. The log-transformed initial luminosity, $\theta$, is assumed to be a constant and the degradation rate $\lambda$ varies from unit-tounit, which reasonably fits the lognormal distribution, $L N\left(\mu, \sigma^{2}\right)$.

The distribution of $X(t)$ is required when investigating the optimal specification limit $\eta$ at the burn-in time $t_{0}$, and predicting the reliability of light display devices at any given time $t \quad\left(t \geq t_{0}\right)$, which can be assessed by the probability that the luminosity is greater than the failure

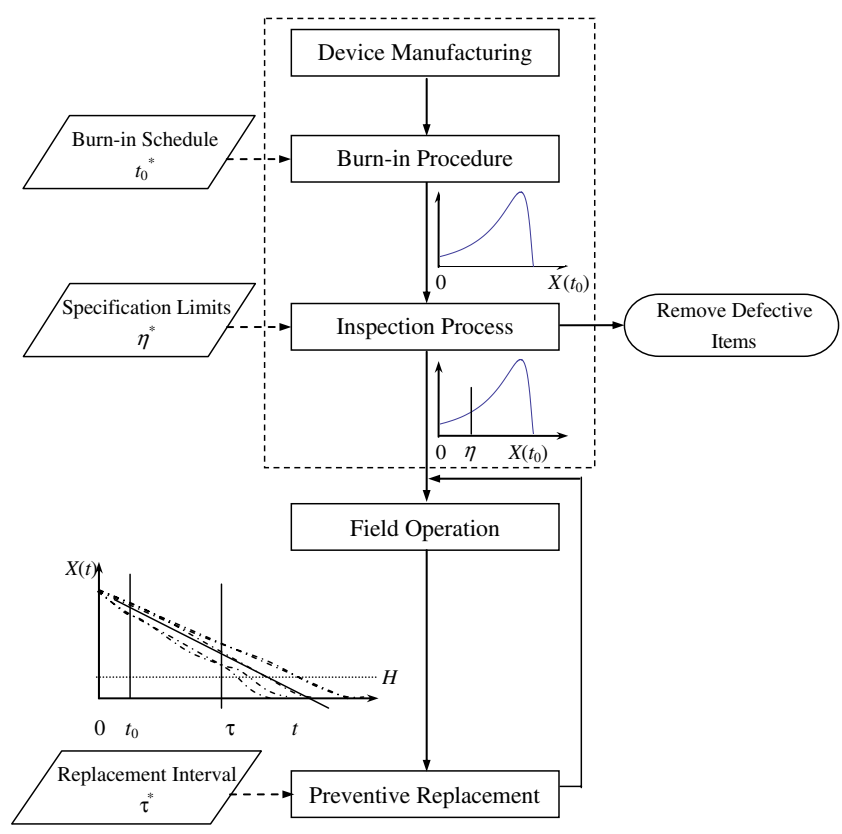

Fig. 1 The manufacturing and operating process of light devices 
threshold. Based on Eq. 1, we developed the cumulative distribution function (cdf) of $X(t)$ as [27]

$$
\begin{aligned}
F_{X}(x ; t) & =1-F_{\lambda}\left(\frac{\theta-x}{t}\right) \\
& =1-\Phi\left(\frac{\ln (\theta-x)-(\ln t+\mu)}{\sigma}\right), \quad x \in(-\infty, \theta),
\end{aligned}
$$

and the probability density function (pdf) of $X(t)$ is determined to be

$$
\begin{aligned}
f_{X}(x)= & \frac{1}{(\theta-x) \sqrt{2 \pi} \sigma} \\
& \exp \left(-\frac{(\ln (\theta-x)-(\ln t+\mu))^{2}}{2 \sigma^{2}}\right), x \in(-\infty, \theta) .
\end{aligned}
$$

This implies that $X(t)$ follows a negative shifted lognormal distribution, which is generalized from the lognormal distribution $[28,29]$.

Let $p$ denote the specified percentage of the initial luminosity that indicates the threshold for failures of light display devices. $p$ is the proportion decrease of luminosity once the light device is fielded after burn-in, e.g., $50 \%$, $60 \%$. Since each light is degrading at a random rate, the luminosity of units that are fielded is a variable. The corresponding failure threshold, $H$, for the degradation characteristic, $X(t)$, is derived from Eq. 1 as

$H=\left\{X(t) ; p=\frac{\Lambda(t)}{\Lambda\left(t_{0}\right)}\right\}$, or

$H=\ln \left(p \Lambda\left(t_{0}\right)\right)=\ln p+X\left(t_{0}\right)=\ln p+\theta-\lambda t_{0}$.

Since $\lambda$ is a lognormal-distributed random variable, it implies that the failure threshold, $H$, is also random among units, rather than a fixed value that is used in most degradation-based reliability analysis. Degradation modeling with a random failure threshold that follows a normal distribution has been discussed in Wang and Coit [30]. Based on Eq. 4, it can be proven that $H$ follows a negative shifted lognormal distribution when $\lambda$ fits a lognormal distribution.

The reliability of a device at any time $t$ can then be assessed by the probability that $X(t)$ is higher than the failure threshold [21]:

$R(t)=P(T>t)=P(X(t)>H)$.

However, this estimation of reliability is only valid when no quality inspection is conducted, i.e., all the produced units are shipped directly to field operation. When all units are inspected after the burn-in procedure, a different reliability estimation is required that is based on conditional reliability function. Light devices that experience higher levels of performance degradation are removed from the population and the remaining population has a truncated distribution, which results in a different reliability function.

\subsection{Impact of quality inspection on reliability}

The reliability function without quality inspection is derived in this section, followed by the derivation of the reliability function with quality inspection after the burn-in procedure. This comparison clearly shows the impact of quality inspection on the reliability estimation, which further verifies the necessity of an integrated methodology for quality inspection and preventive maintenance policies.

\subsubsection{Reliability estimation without quality inspection}

Consider the situation where no quality inspection is conducted after the burn-in procedure. Based on Eq. 5, the reliability function is derived as

$$
\begin{aligned}
R(t) & =P(T>t)=P(X(t)>H)=P\left(\theta-\lambda t>\ln p+\theta-\lambda t_{0}\right) \\
& =P\left(\lambda<\frac{-\ln p}{t-t_{0}}\right)=P\left(\ln \lambda<\ln \left(\frac{-\ln p}{t-t_{0}}\right)\right) \\
& =1-\Phi\left(\frac{\ln \left(t-t_{0}\right)-(\ln (-\ln p)-\mu)}{\sigma}\right) . \quad t>t_{0} .
\end{aligned}
$$

The cdf of failure time, $T$, is therefore

$F_{T}(t)=\Phi\left(\frac{\ln \left(t-t_{0}\right)-(\ln (-\ln p)-\mu)}{\sigma}\right), \quad t>t_{0}$,

and the pdf of $T$ is

$f_{T}(t)=\frac{1}{\sigma\left(t-t_{0}\right)} \phi\left(\frac{\ln \left(t-t_{0}\right)-(\ln (-\ln p)-\mu)}{\sigma}\right), \quad t>t_{0}$.

This proves that the failure time $T$ follows a shifted lognormal distribution,

$T \sim$ Shifted $L N\left((\ln (-\ln p)-\mu), \sigma, t_{0}\right)$.

\subsubsection{Reliability estimation with quality inspection}

In practice, the luminosity of light display devices is inspected after the burn-in procedure, and the units whose luminosity is below a lower specification limit are classified as defective items and removed from field operation. With this truncation on $X(t)$, the reliability is the probability that $X(t)$ is higher than $H$ given that the unit passes the quality 
inspection. Therefore, the conditional reliability function is given as

$$
\begin{aligned}
R\left(t \mid X\left(t_{0}\right)>\eta\right) & =P\left(X(t)>H \mid X\left(t_{0}\right)>\eta\right) \\
& =\frac{P\left(\lambda<\min \left\{\frac{-\ln p}{t-t_{0}}, \frac{\theta-\eta}{t_{0}}\right\}\right)}{P\left(\lambda<\frac{\theta-\eta}{t_{0}}\right)} .
\end{aligned}
$$

The last step is obtained based on Eqs. 1 and 4. As $\lambda$ follows a lognormal distribution, $L N\left(\mu, \sigma^{2}\right)$, the conditional reliability in Eq. 9 can be further derived as a step function:

$$
\begin{aligned}
R\left(t \mid X\left(t_{0}\right)>\eta\right)= & \frac{\Phi\left(\left(\ln \left(\min \left\{\frac{-\ln p}{t-t_{0}}, \frac{\theta-\eta}{t_{0}}\right\}\right)-\mu\right) / \sigma\right)}{\Phi\left(\left(\ln \left(\frac{\theta-\eta}{t_{0}}\right)-\mu\right) / \sigma\right)} \\
& =\left\{\begin{array}{cl}
\frac{1-\Phi\left(\left(\ln \left(t-t_{0}\right)-\ln (-\ln p)+\mu\right) / \sigma\right)}{\Phi\left(\left(\ln \left(\frac{\theta-\eta}{t_{0}}\right)-\mu\right) / \sigma\right)}, & t>t_{0}\left(1-\frac{\ln p}{\theta-\eta}\right) . \\
1, & , t \leq t_{0}\left(1-\frac{\ln p}{\theta-\eta}\right) .
\end{array}\right.
\end{aligned}
$$

Then, the pdf of $T$ given $X\left(t_{0}\right)>\eta$ is expressed as follows:

$$
f_{T}\left(t \mid X\left(t_{0}\right)>\eta\right)=\left\{\begin{array}{cl}
\frac{\phi\left(\left(\ln \left(t-t_{0}\right)-\ln (-\ln p)+\mu\right) / \sigma\right)}{\sigma\left(t-t_{0}\right) \Phi\left(\left(\ln \left(\frac{\theta-\eta}{t_{0}}\right)-\mu\right) / \sigma\right)}, & t>t_{0}\left(1-\frac{\ln p}{\theta-\eta}\right) . \\
0 & , t \leq t_{0}\left(1-\frac{\ln p}{\theta-\eta}\right) .
\end{array}\right.
$$

This demonstrates that the random variable $T$ has a truncated shifted lognormal distribution, which is different from the shifted lognormal distribution given in Eq. 8. It can be-concluded that the implementation of quality inspection significantly impacts reliability and failure time distributions. Therefore, quality inspection and maintenance policies should be determined simultaneously rather than separately or sequentially as is often done in practice. A case study of fluorescent lamps is used to illustrate the impact of quality inspection on reliability.

\subsection{Quality and reliability evaluation and optimization}

A comprehensive performance measure should be used that can simultaneously reward high reliability during field operation and penalize quality loss during manufacturing. We develop an expected total cost model that captures the expected quality cost, failure cost and replacement cost during the device life cycle, as shown in Fig. 1. By minimizing this expected total cost over the expected usage time, three decision variables, burn-in time $t_{0}$, specification limit $\eta$ and replacement interval $\tau$, can be determined.

During the quality inspection of light display devices, three quality-related costs are considered: quality losses due to the deviation from the ideal value, scrap cost, and inspection cost [23]. The quality loss of each unit can be measured by a quality loss function, which can be chosen based on the type of the quality characteristic: the smaller the better (S-type), the larger the better (L-type) or the target the best (T-type). As the luminosity of light display devices is an L-type quality characteristic in this case, its quality loss function can be expressed as $L\left(X\left(t_{0}\right)\right)=$ $k / X\left(t_{0}\right)^{2}$, where $k$ is the coefficient that transforms deviations into economic values. The quality loss can be estimated using the expected value of $L\left(X\left(t_{0}\right)\right)$ based on Eq. 3:

$$
\begin{aligned}
C_{Q}\left(\eta, t_{0}\right)= & \int_{\eta}^{\theta} L\left(x ; t_{0}\right) f_{X}\left(x ; t_{0}\right) d x \\
= & \int_{\eta}^{\theta} \frac{k}{x^{2}(\theta-x) \sqrt{2 \pi} \sigma} \\
& \exp \left(-\frac{\left(\ln (\theta-x)-\left(\ln t_{0}+\mu\right)\right)^{2}}{2 \sigma^{2}}\right) d x,
\end{aligned}
$$

where $f_{X}\left(x ; t_{0}\right)$ is the pdf of the log-transformed luminosity at the end of burn-in process, and $\eta$ is the lower specification limit (LSL) to be determined. If an observed measurement is below the LSL, the unit is scrapped as a defective item. Let $q\left(\eta, t_{0}\right)$ be the fraction of conforming units, which corresponds to the area under the pdf curve bounded by the LSL. Based on Eq. 2, $q\left(\eta, t_{0}\right)$ is derived as

$q\left(\eta, t_{0}\right)=\int_{\eta}^{\theta} f_{X}\left(x ; t_{0}\right) d x=\Phi\left(\frac{\ln (\theta-\eta)-\left(\ln t_{0}+\mu\right)}{\sigma}\right)$.

If the scrap cost per unit is denoted as $s$, then the scrapped portion of $\left(1-q\left(\eta, t_{0}\right)\right)$ results in an expected scrap cost of $C_{S}\left(\eta, t_{0}\right)=\left(1-q\left(\eta, t_{0}\right)\right) s$. The inspection cost per unit is denoted as $C_{I}$, which is a constant independent of $\eta$. Therefore, the total expected quality cost per unit incurred at the manufacturing phase is expressed as:

$Q C\left(\eta, t_{0}\right)=C_{Q}\left(\eta, t_{0}\right)+C_{S}\left(\eta, t_{0}\right)+C_{I}$.

The system reliability can be evaluated considering the cost-of-failure approach [31]. The cost of an unexpected failure in field operation is assumed to be a constant value, $f_{c}$, which is independent of the time-tofailure and can be estimated as a one-time repair cost. The system reliability cost of a replacement cycle is then evaluated by the expected failure $\operatorname{cost}\left(F C\left(\eta \cdot \tau, t_{0}\right)\right)$ and it is given by

$F C\left(\eta, \tau, t_{0}\right)=f_{c}\left(1-R\left(\tau \mid X\left(t_{0}\right)>\eta\right)\right)$.

If the system fails before the replacement interval $\tau$, then it must be replaced by an operational replacement and the 


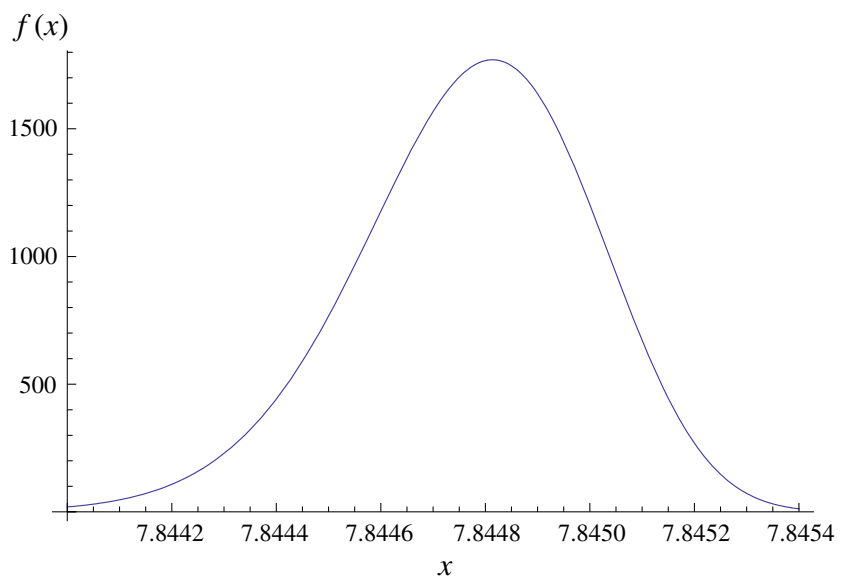

Fig. 2 Probability density of $X\left(t_{0}\right)$ at $t_{0}=100 \mathrm{~h}$

cost is $f_{c}+R C$, where $R C$ is the replacement cost. Alternatively, if it has not failed by $\tau$, it should be replaced based on economic considerations and the cost is just $R C$. Thus, the expected total failure and replacement cost at $\tau$ is $F C\left(\eta, \tau, t_{0}\right)+R C$.

The expected total cost needs to be minimized over the expected usage time of light display devices. Based on Eq. 11, the expected usage time is given as (see Appendix)

$$
\begin{aligned}
& E\left[U \mid \eta, t_{0}, \tau\right] \\
& =\frac{\frac{1}{\sigma} \int_{t_{0}}^{\tau} \phi\left(\frac{\ln \left(t-t_{0}\right)-(\ln (-\ln p)-\mu)}{\sigma}\right) d t+t_{0} \Phi\left(\frac{\ln \left(\tau-t_{0}\right)-(\ln (-\ln p)-\mu)}{\sigma}\right)}{\Phi\left(\left(\ln \left(\frac{\eta-\theta}{-t_{0}}\right)-\mu\right) / \sigma\right)} .
\end{aligned}
$$

The burn-in cost, $B C\left(t_{0}\right)$, is approximated as a linear function of the burn-in period $t_{0}$, which is given as $B C\left(t_{0}\right)=b t_{0}$. Then the expected total cost per unit expected usage time is given as

$$
T C\left(\eta, \tau, t_{0}\right)=\frac{B C\left(t_{0}\right)+Q C\left(\eta, t_{0}\right)+F C\left(\eta, \tau, t_{0}\right)+R C}{E\left[U \mid \eta, t_{0}, \tau\right]} .
$$

Thus, the constrained optimization model that minimizes the expected total cost rate due to quality loss and reliability cost during the system life cycle can be expressed as

$$
\left(\eta^{*}, \tau^{*}, t_{0}^{*}\right)=\arg \min \left\{T C\left(\eta, \tau, t_{0}\right)\right\}
$$$$
\text { subject to } 0<\eta<\theta, \quad L_{\tau} \leq \tau \leq U_{\tau}, \quad L_{t_{0}} \leq t_{0} \leq U_{t_{0}} \text {, }
$$

where $L_{\tau}$ and $U_{\tau}$ are the lower and upper bounds of the replacement interval specified by customers or designers, and $L_{t 0}$ and $U_{t 0}$ are the specified lower and upper bounds of the burn-in time.

Simulated annealing [32], sequential quadratic programming (SQP) $[33,34]$ and other optimization algorithms can be implemented to solve the constrained nonlinear problem in Eq. 18. For the case study in the next section, simulated annealing algorithm is utilized to solve the problem, since it is superior for optimization models with complicated objective functions [35].

\section{Numerical example}

Consider a fluorescent lamp design that is subject to luminosity degradation over its life cycle. The parameters in the degradation path can be estimated from the experimental results given in [19]. Under the optimal setting of experimental factors, the expected value of the initial log-transformed luminosity, $\theta$, is estimated as 7.84664. The mean and standard deviation of $\ln (\lambda)$ are estimated to be -10.8956 and 0.1225 , respectively, i.e., $\lambda \sim L N\left(-10.8956,0.1225^{2}\right)$. As previously stated, the industry's standard definition for the lifetime of fluorescent lamps is the time $t$ when a lamp's luminosity $\Lambda(t)$ falls below $60 \%$ of its initial brightness when fielded (at the end of the burn-in period $t_{0}$ ), which implies that $p$ equals to 0.6 .

As described in [19], a lamp after 100 hours burn-in period is declared as non-defective if its output luminosity exceeds 2500 lumen. These are the burn-in time and the specification limit used in the original setting, i.e., $t_{0}=100 \mathrm{~h}$ and $\eta=7.8240$. We will compare the resulting system performance between these original setting and the optimal setting provided by our model. The lamp is replaced at 30,000 hours based on the reliability estimation, i.e., $\tau=30,000 \mathrm{~h}$. In addition, we have the following parameter settings: $b=0.5, k=5500, s=50, C_{I}=0.1, f_{c}=2500$, and $R C=50$. These are typical or nominal values selected to demonstrate the optimization model. The feasible boundaries for the decision variables, selected based on the

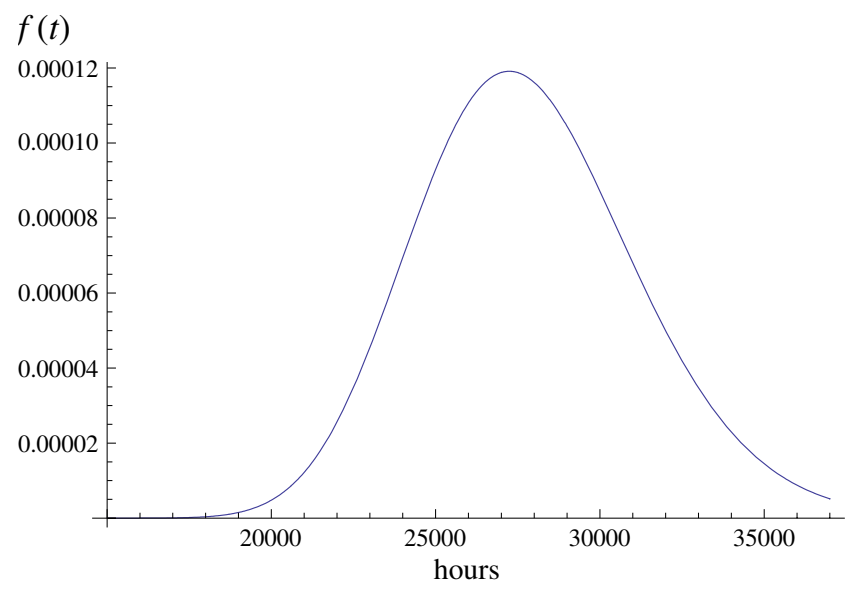

Fig. 3 Probability density of failure time $T$ with quality inspection 
practical constraints specified by designers or customers, are given as:

$\eta \in[0,7.84664], \quad \tau \in[10,000,150,000], \quad t_{0} \in[100,200]$.

Using simulated annealing, the optimal solution is obtained as $\eta=7.8408, \tau=61,000 \mathrm{~h}$, and $t_{0}=100 \mathrm{~h}$, respectively. The performance comparison between the optimal setting and the original setting indicates that the total cycle cost per usage lifetime decreases dramatically by $96.3 \%$ from $\$ 0.0965 / \mathrm{h}$ to $\$ 2.6257 / \mathrm{h}$.

The probability density functions of $X\left(t_{0}\right)$ and failure time $T$ are shown in Figs. 2 and 3, respectively. Figure 2 shows the probability density function of the logarithm of luminous flux at the end of burn-in process, $X\left(t_{0}\right)$, as given in Eq. 3. If the specification limit $\eta$ is set to be the optimal value 7.8408 , the left portion of the specification limit will be scrapped as defective items after burn-in. The probability density function of the failure time with quality inspection procedure is given in Fig. 3. Because the quality inspection procedure is implemented after the burn-in process, the probability of failure equals to zero when the time to failure is less than $8,847 \mathrm{~h}$, as given in Eq. 11. This implies that the quality inspection policy is an effective way to improve the reliability of the device.

\section{Concluding remarks}

Based on the analysis of the degradation path of light display devices and the distribution of the degradation characteristic, we investigate the integrated optimization of reliability and quality for light display devices. The reliability functions and failure time distributions with and without quality inspection are developed to show the interrelationship between quality inspection and maintenance policies. It is concluded that the quality inspection policy has a significant impact on the reliability behavior of light devices. An integrated approach to determine the burn-in, quality inspection and preventive maintenance policies simultaneously is then proposed. The quality loss cost and unexpected failure cost during the usage lifetime are evaluated to develop the mathematic model.

Our previous work on microengines [21] differs from the study in this paper in several respects, although the basic framework for the two applications is to jointly optimize quality and reliability policies to achieve minimum total cost. For the microengine application, the distribution of degrading characteristic, $X(t)$, follows a normal distribution, while for light display devices, $X(t)$ follows a negative shifted lognormal distribution. In addition, the failure threshold is a fixed value for the microengine application, while it is a random variable for light display devices, which makes the modeling of reliability and failure time distinctly different and more challenging.

\section{Appendix}

The expected usage time in Eq. 16 is derived based on Eq. 11 as follows.

$$
\begin{aligned}
E\left[U \mid \eta, t_{0}, \tau\right] & =\int_{t_{0}}^{\tau} t f_{T}\left(t \mid X\left(t_{0}\right)>\eta\right) d t=\int_{t_{0}}^{\tau} \frac{t \phi\left(\left(\ln \left(t-t_{0}\right)-(\ln (-\ln p)-\mu)\right) / \sigma\right)}{\sigma\left(t-t_{0}\right) \Phi\left(\left(\ln \left(\frac{\eta-\theta}{-t_{0}}\right)-\mu\right) / \sigma\right)} d t \\
& =\frac{1}{\sigma \Phi\left(\left(\ln \left(\frac{\eta-\theta}{-t_{0}}\right)-\mu\right) / \sigma\right)}\left[\int_{t_{0}}^{\tau} \phi\left(\frac{\ln \left(t-t_{0}\right)-(\ln (-\ln p)-\mu)}{\sigma}\right) d t+\int_{-\infty}^{\ln \left(\tau-t_{0}\right)} t_{0} \phi\left(\frac{x-(\ln (-\ln p)-\mu)}{\sigma}\right) d x\right] \\
& =\frac{1}{\Phi\left(\left(\ln \left(\frac{\eta-\theta}{-t_{0}}\right)-\mu\right) / \sigma\right)}\left[\frac{1}{\sigma} \int_{t_{0}}^{\tau} \phi\left(\frac{\ln \left(t-t_{0}\right)-(\ln (-\ln p)-\mu)}{\sigma}\right) d t+t_{0} \Phi\left(\frac{\ln \left(\tau-t_{0}\right)-(\ln (-\ln p)-\mu)}{\sigma}\right)\right]
\end{aligned}
$$

\section{References}

1. Tanner DM, Dugger MT (2003) Wear mechanisms in a reliability methodology. SPIE's Proceedings, Vol. 4980: Reliability, Testing, Characterization of MEMS/MOEMS. San Jose, C, pp 22-40

2. Bae SJ, Kvam PH (2006) A change-point analysis for modeling incomplete burn-in for light displays. IIE Trans 38:489-498. doi:10.1080/074081791009068
3. Lu CJ, Meeker WQ (1993) Using degradation measures to estimate a time-to-failure distribution. Technometrics 35(2):161174. doi: $10.2307 / 1269661$

4. Meeker WQ, Escobar LA, Lu CJ (1998) Accelerated degradation tests: modeling and analysis. Technometrics 40(2):89-99. doi: $10.2307 / 1270643$

5. Singpurwalla ND (1995) Survival in dynamic environments. Stat Sci 10(1):86-103. doi:10.1214/ss/1177010132 
6. Kharoufeh JP (2003) Explicit results for wear processes in a Markovian environment. Oper Res Lett 31:237-244. doi:10.1016/ S0167-6377(02)00229-8

7. Kharoufeh JP, Cox SM (2005) Stochastic models for degradationbased reliability. IIE Trans 37(6):533-542. doi:10.1080/ 07408170590929009

8. Lu CJ, Park J, Yang Q (1997) Statistical inference of a time-tofailure distribution derived from linear degradation data. Technometrics 39(4):391-400. doi:10.2307/1271503

9. Gebraeel NZ, Lawley MA (2008) A neural network degradation model for computing and updating residual life distributions. IEEE Trans Automat Sci Eng 5(1):154-163. doi:10.1109/ TASE.2007.910302

10. Gebraeel NZ et al (2004) Residual life predictions from vibrationbased degradation signals: a neural network approach. IEEE Trans Ind Electron 51(3):694-700. doi:10.1109/TIE.2004.824875

11. Gebraeel NZ et al (2005) Residual-life distributions from component degradation signals: a Bayesian approach. IIE Trans 37:543-557. doi:10.1080/07408170590929018

12. Gebraeel NZ (2006) Sensory-updated residual life distributions for components with exponential degradation patterns. IEEE Trans Automat Sci Eng 3(4):382-393. doi:10.1109/TASE.2006.876609

13. Huang W, Dietrich DL (2005) An alternative degradation reliability modeling approach using maximum likelihood estimation. IEEE Trans Reliab 54(2):310-317. doi:10.1109/TR.2005.845965

14. Grall A et al (2002) Continuous-time predictive-maintenance scheduling for a deteriorating system. IEEE Trans Reliab 51 (2):141-150. doi:10.1109/TR.2002.1011518

15. Liao H, Elsayed EA, Chan LY (2006) Maintenance of continuously monitored degrading systems. Eur J Oper Res 175:821-835. doi:10.1016/j.ejor.2005.05.017

16. Lu S, Tu Y-C, Lu H (2007) Predictive condition-based maintenance for continuously deteriorating systems. Qual Reliab Eng Int 23 (1):71-81. doi:10.1002/qre.823

17. Drapella A, Kosznik S (2002) Short communication: combining preventive replacement and burn-in procedures. Qual Reliab Eng Int 18:423-427. doi:10.1002/qre.482

18. Jiang R, Jardine AKS (2007) An optimal burn-in preventivereplacement model associated with a mixture distribution. Qual Reliab Eng Int 23:83-93. doi:10.1002/qre.816

19. Tseng ST, Hamada M, Chiao CH (1995) Using degradation data to improve fluorescent lamp reliability. J Qual Technol 27(4):363-369

20. Tannas LE (1985) Flat-Panel displays and CRTs. Van Nostrand Reinhold, New York
21. Peng H, Feng Q, Coit DW (2009) Simultaneous quality and reliability optimization for microengines subject to degradation. IEEE Trans Reliab 58(1):98-105

22. Langley FJ, Robinson CA, Passero RA (1999) Automatic electrooptical testing of automobile dashboard displays in a factory environment. Test Conference International, Washington, DC

23. Feng Q (2005) Integrated statistical and optimization strategies for the improvement of six sigma methodology, $\mathrm{PhD}$ Dissertation. University of Washington, Seattle, WA

24. Feng Q, Kapur KC (2006) Economic development of specifications for $100 \%$ inspection based on asymmetric quality loss functions. IIE Trans 38:659-669. doi:10.1080/07408170600692226

25. Feng Q, Kapur KC (2006) Economic design of specifications for $100 \%$ inspection with imperfect measurement systems. Qual Technol Quant Manag 3(2):127-144

26. Wang H (2001) A survey of maintenance policies of deteriorating systems. Eur J Oper Res 139:469-489. doi:10.1016/S0377-2217(01) 00197-7

27. Casella G, Berger RL (2002) Statistical inference, 2nd edn. Pacific Grove, Australia

28. Chen G (1995) Generalized log-normal distributions with reliability application. Comput Stat Data Anal 19:309-319. doi:10.1016/01679473(93)E0047-8

29. Borovkova S, Ferry JP (2007) Asian basket options and implied correlations in oil markets. The Fourth IASTED International Conference on Financial Engineering and Applications, Berkeley, CA

30. Wang P, Coit DW (2007) Reliability and degradation modeling with random or uncertain failure threshold. Annual Reliability and Maintainability Symposium (RAMS), Orlando, FL, pp 392-397

31. Todinov MT (2004) Reliability analysis and setting reliability requirements based on the cost of failure. Int J Reliab Qual Saf Eng 11(3):273-299. doi:10.1142/S0218539304001518

32. Kirkpatrick S, Gelatt CD, Vecchi MP (1983) Optimization by simulated annealing. Science 220(4598):671-680. doi:10.1126/ science.220.4598.671

33. Zhu Z (2006) A simple feasible SQP algorithm for inequality constrained optimization. Appl Math Comput 182(2):987-998. doi:10.1016/j.amc.2006.04.073

34. Burke JV (1989) A sequential quadratic programming method for potentially unfeasible mathematical programs. J Math Anal Appl 139(2):319-351. doi:10.1016/0022-247X(89)90111-X

35. Neptune RR (1999) Optimization algorithm performance in determining optimal controls in human movement analyses. J Biomech Eng 121(2):249-252. doi:10.1115/1.2835111 